\title{
Relationship of Total Suspended Particulate Dust Levels, Personal Protective Equipment, and Individual Characteristics with. Breathing Respiratory Complaints at Benowo Landfill Surabaya
}

\author{
Herman Bagus Dwicahyo' ${ }^{1}$, Pudji Rahmawati ${ }^{2}$, Syamsiar S. Russeng ${ }^{3}$, Lilis Sulistyorini', Abdul Rohim Tualeka ${ }^{1}$ \\ 'Department of Occupational Health and Safety, Faculty of Public Health, Airlangga University, \\ Surabaya, Indonesia; ' Department of Development of Islamic Society, State Islamic University Sunan \\ Ampel, Surabaya, Indonesia; ${ }^{3}$ Departement of Occupational Health and Safety, Faculty of Public Health, \\ Hassanuddin University Indonesia, Makassar, Indonesia; ${ }^{+}$Department of Environmental Health, Faculty \\ of Public Health, Airlangga University, Surabaya, Indonesia
}

\begin{abstract}
A landfill can have an impact on environmental quality such as air pollution from dust and gas produced from the anaerobic decomposition process, especially if waste disposal uses an open dumping system ${ }^{1}$. The results of the preliminary study showed that scavengers in the final processing of garbage had not used PPE (Personal Protective Equipment) such as masks and did not use hand protectors. Many health complaints felt by them are low back pain and headache. This research was observational, the study design used was a cross-sectional study design. The location of the study was carried out at the Surabaya Benowo waste landfill, the sample in the study was scavengers of women who worked at the Surabaya Benowo waste landfill aged 15-64 years. The method of measuring TSP (Total Suspended Particulate) dust using laboratory tests with gravimetric methods, data on the use of PPE mask and respiratory complaints were obtained through questionnaires. Statistical tests were used to see strong relationships using Kendall's tau-b with a significance value of $\alpha=0.05$. The results of the air quality test in the form of TSP dust content at the work site of the scavengers showed the results of $0.0972 \mathrm{mg} / \mathrm{Nm} 3$ which meant that TSP dust levels did not exceed environmental quality standards. Of the 37 scavenger respondents, 13 people $(24 \%)$ experienced moderate respiratory complaints and 24 people $(65 \%)$ experienced mild respiratory complaints. Characteristics of individual scavengers associated with respiratory complaints were cigarette exposure $(\mathrm{Sig}=0.025)$ and disease history $(\mathrm{Sig}=0.00)$. There was no significant relationship between the use of PPE with respiratory complaints suffered by scavengers at Benowo landfill Surabaya.
\end{abstract}

Keywords: TSP Dust, Respiratory Complaints, Individual Characteristics.

\section{Introduction}

The landfill is a place where waste reaches is the last stage in its management from the start in the source, collection, transfer or transportation, processing to disposal.

\section{Correspondence Author:}

Abdul Rohim Tualeka

Department of Occupational Health and Safety,

Faculty of Public Health, Airlangga University, 60115 Surabaya, East Java, Indonesia

Phone: +6281333519732

Email: inzut.tualeka@gmail.com; abdu-r-t@fkm.unair
Open dumping landfill will be a source of income for local residents, especially for people who do not have jobs and choose to become scavengers at the final processing of garbage.

The landfill can have an impact on environmental quality and scavenger such as air pollution from dust and gas produced from the anaerobic decomposition process, especially if waste disposal uses an open dumping system ${ }^{1}$.

Air pollution is pollution inside and outside the room either by chemical agents, physics, or biology that changes the natural characteristics of an environment ${ }^{2}$. 
The results of a preliminary study conducted on December 23, 2015, showed that scavengers at Benowo landfill Surabaya did not use PPE such as masks and hand protectors. Many health complaints felt by them are back pain and headache. Low back pain and fatigue occur because their work is not ergonomic, such as constantly looking down to pick up garbage long time, and dizziness can be caused by sun exposure from morning to evening when they work.

\section{Material and Method}

Judging from the data collection method, this research is observational. The study design used in this study was a cross-sectional study design.

The location of the study was carried out at Benowo landfill Surabaya. precisely at the South IIB waste point. The sample in the study was scavengers of women who worked at Benowo landfill Surabaya 15-64 years old. The determine sample to be carried out during this research is by using Simple Random Sampling.

The variables in this study consist of independent variables and dependent variables. The independent variable in this study is TSP (Total Suspended Particulate) Dust, while the dependent variable is respiratory complaints.

How to measure the independent variables and dependent variables in this study include TSP Dust Based on East Java Governor Regulation No. 10 of 2009 using laboratory tests with Gravimetric, PPE (Self-Protective) mask methods through questionnaires and respiratory complaints through questionnaires. Statistical tests using Kendall's tau-b with a significance value of $\alpha=0.05$

\section{Findings}

Benowo Surabaya landfill is located on $\mathrm{Jl}$. Romokalisari Romokalisari Village, District Benowo Surabaya. has an area of 38.7 hectares, 24 of which are used for sanitary landfills consisting of 5 terminals and the rest are used for public facilities, there are green beams which are used as odor catchers around the landfill site and along to the terminal.

Every month there are only 2 terminals that are used for loading and unloading garbage, 3 are carried out by fireplaces and backfillers use the land. Garbage that is in Benowo landfill comes from all over the Surabaya area, the volume of waste that comes in a landfill is around 1,200 tons/day.
The results of the measurement of ambient air quality at Benowo Surabaya landfill show that the dust parameters are $0.0972 \mathrm{mg} / \mathrm{Nm} 3$ where the results are still below the quality standards set by Rule. Gub. East Java No. 10 the year 2009. Coarse dust particles can be filtered by a hair in the nostrils, while fine dust particles will become entangled in the mucous layer. In addition, high levels of TSP dust can endanger health because it can cause obstruction and restriction from the airways ${ }^{3}$.

Respiratory complaints in this study diseases that have been or are being experienced by scavengers curing the last three months, including coughing, phlegm, wheezing, shortness of breath, flu and chest pain.

Mild respiratory complaints in this study included mild coughing less than 4-6 times a day, flu for $<3$ weeks, and coughing up phlegm $<3$ months. While moderate respiratory complaints in this study include mild coughing up to 4-6 times a day, wheezing or wheezing, experiencing shortness of breath so difficult to walk, flu $>3$ weeks, coughing with phlegm for $>3$ months and chest pain.

Table 1: Scavengers Mild And Moderate Respiratory Complain

\begin{tabular}{|c|c|c|}
\hline Respiratory Complaints & Total & Percent (\%) \\
\hline Lightweight & 24 & 65 \\
\hline Medium & 13 & 35 \\
\hline Weight & 0 & 0 \\
\hline Total & 37 & 100 \\
\hline
\end{tabular}

From the table above it can be seen that scavengers who experienced mild respiratory complaints were 24 people $(65 \%)$, while scavengers with moderate respiratory complaints were 13 people (35\%).

Coughing is the most common symptom of respiratory problems. Stimulations that usually cause coughing are mechanical and chemical stimulation, dust inhalation, smoke, and small foreign objects are the most common causes of coughing.

The relationship of scavenger characteristics in the form of using PPE with respiratory complaints in this study showed that scavengers, using PPE experienced mild respiratory complaints of 13 people $(65 \%)$ and severe respiratory complaints of 7 people $(35 \%)$. Whereas with scavengers who did not use PPE 
experienced respiratory complaints as many as 11 people $(65 \%)$ and experienced moderate respiratory complaints as many as 6 people (35\%). The results of statistical tests obtained $\mathrm{Sig}=0.985$, it can be interpreted that there is no relationship between the use of PPE with complaints of respiratory scavengers landfill Benowo Surabaya.

This is because the masks used by scavengers are masks that are specifically not intended to prevent exposure to harmful gases or dust, scavengers only use ordinary cloth or their veils for women to use to cover their noses, this is not the same as having no effect on exposure to incoming gas in the respiratory tract.

Table 2: Age Of Cavengers Mild And Moderate Respiratory Complain

\begin{tabular}{|c|c|c|c|c|c|c|c|}
\hline \multirow{3}{*}{$\begin{array}{l}\text { Age } \\
\text { (th) }\end{array}$} & \multicolumn{4}{|c|}{$\begin{array}{l}\text { respiratory } \\
\text { complaints }\end{array}$} & \multirow{2}{*}{\multicolumn{2}{|c|}{ Total }} & \multirow{3}{*}{ Sig } \\
\hline & \multicolumn{2}{|c|}{ Mild } & \multicolumn{2}{|c|}{ Medium } & & & \\
\hline & $\mathbf{n}$ & $\%$ & $\mathbf{n}$ & $\%$ & $\mathbf{n}$ & $\%$ & \\
\hline 15-24th & 2 & 33 & 4 & 67 & 6 & 100 & \multirow{5}{*}{0,361} \\
\hline 25-34th & 9 & 75 & 3 & 25 & 12 & 100 & \\
\hline 35-44th & 9 & 69 & 4 & 31 & 13 & 100 & \\
\hline 45-54th & 3 & 60 & 2 & 40 & 5 & 100 & \\
\hline 55-64th & 1 & 100 & 0 & 0 & 1 & 100 & \\
\hline
\end{tabular}

From the table, it can be seen that the scavengers mild respiratory complaints are the highest in the 25-34 age group of $(75 \%)$. Whereas the biggest scavengers who experience moderate respiratory complaints are in the age group $15-24$ by $67 \%$.

Jatibarang landfill in Semarang, the results showed that complaints of health problems were more experienced by $43.3 \%$ female scavengers aged less than 39 years (young age) compared to aged female scavengers $\geq 39$ years old (old age $)^{4}$.

From the table, it can be seen that scavengers with a working period of $\leq 5$ years experience mild respiratory complaints as much as $60 \%$ while scavengers with a working period of $>5$ years experience mild respiratory complaints more than $68 \%$. And for scavengers with a working period of $\leq 5$ years who experience moderate respiratory complaints as much as $40 \%$ while those for scavengers who have a working period $>5$ th experience moderate breathing complaints as much as $32 \%$.
Table 3: Working Time Scavengers Mild And Moderate Respiratory Complain

\begin{tabular}{|c|c|c|c|c|c|c|c|}
\hline \multirow{3}{*}{$\begin{array}{c}\text { Working } \\
\text { Time }\end{array}$} & \multicolumn{4}{|c|}{$\begin{array}{l}\text { Respiratory } \\
\text { complaints }\end{array}$} & \multirow{2}{*}{\multicolumn{2}{|c|}{ Total }} & \multirow{3}{*}{ Sig } \\
\hline & \multicolumn{2}{|c|}{ Mild } & \multicolumn{2}{|c|}{ Medium } & & & \\
\hline & $\mathrm{n}$ & $\%$ & $\mathrm{n}$ & $\%$ & $\mathrm{n}$ & $\%$ & \\
\hline$\leq 5$ tahun & 9 & 60 & 6 & 40 & 15 & 100 & \multirow{2}{*}{0,614} \\
\hline$>5$ tahun & 15 & 68 & 7 & 32 & 22 & 100 & \\
\hline
\end{tabular}

Table 4: Long Exposure Scavengers Mild And Moderate Respiratory Complain

\begin{tabular}{|c|c|c|c|c|c|c|c|}
\hline \multirow{2}{*}{$\begin{array}{c}\text { Long } \\
\text { Exposure }\end{array}$} & \multicolumn{4}{|c|}{$\begin{array}{c}\text { Respiratory } \\
\text { complaints }\end{array}$} & \multicolumn{2}{|c|}{ Total } & \multirow{3}{*}{ Sig } \\
\cline { 2 - 6 } & \multicolumn{2}{|c|}{ Mild } & \multicolumn{1}{|c|}{ Medium } & \multicolumn{2}{|c|}{} \\
\cline { 2 - 7 } & $\mathbf{n}$ & $\%$ & $\mathbf{n}$ & $\%$ & $\mathbf{n}$ & $\%$ & \\
\hline$\leq 8 \mathrm{Jam}$ & 3 & 50 & 3 & 50 & 6 & 100 & \multirow{2}{*}{0,411} \\
\hline$>8 \mathrm{Jam}$ & 21 & 68 & 10 & 32 & 31 & 100 & \\
\hline
\end{tabular}

Most scavengers who experience mild breathing complaints are $>8$ hours of exposure, which is 21 people (68\%), while most scavengers with moderate respiratory complaints at exposure to $\leq 8$ hours are $50 \%$.

The longer a person's exposure is likely the greater the risk of lung disease. This shows that the longer a person's work will be the longer the time for exposure to the pollutant occurs ${ }^{5}$.

Based on the questionnaire results related to individual characteristics that have been distributed to scavengers, it was found that was a significant relationship between exposure to cigarettes and respiratory complaints with a $S i g$ value $=0.025$. From the results of the study, it can also be seen that $100 \%$ of active smokers experience moderate respiratory complaints and $40 \%$ of passive smokers experience moderate breathing complaints and $60 \%$ of passive smokers experience mild breathing complaints.

This is consistent with the research that cigarette exposure is a protective factor for pulmonary dysfunction in employees ${ }^{3}$. Besides that, there is a significant relationship between smoking habits and respiratory disorders ${ }^{6}$.

Based on the results of the research, the results of statistical tests using Kendall's tau-b obtained Sig $=0,000$ so that it can be interpreted that there is a relationship between the history of the disease 
and complaints of scavenger breathing at Benowo Surabaya landfill. In addition, the results of the study also showed that scavengers with a history of $71 \%$ had moderate respiratory complaints and $29 \%$ of scavengers experienced mild respiratory complaints.

The results of this study are in line with the research conducted that workers who have had lung disease are significantly associated with lung function disorders? Likewise with research workers who have a history of pulmonary disease will find it easier to get pulmonary function disorders compared to workers who do not have a history of pulmonary disease ${ }^{8}$.

\section{Conclusion}

1. The results of testing the air quality in the form of TSP dust content at the work site of waste collectors showed the results of $0.0972 \mathrm{mg} / \mathrm{Nm} 3$ that TSP Dust levels did not exceed environmental quality standards according to the East Java Governor Regulation No. 10 of $2009^{9}$.

2. Of the 37 scavenger respondents, 13 people $(24 \%)$ experienced moderate respiratory complaints and 24 people $(65 \%)$ experienced mild respiratory complaints.

3. Characteristics of scavenger individuals associated with scavenger lung physiological disorders, namely cigarette exposure $(\mathrm{Sig}=0.030)$ and disease history $(\mathrm{Sig}=0.00)$. While the characteristics of individual scavengers associated with respiratory complaints were cigarette exposure $(\mathrm{Sig}=0.025)$ and disease history $(\mathrm{Sig}=0.00)$.

4. There was no significant relationship between the use of PPE (Personal Protective Equipment) with respiratory complaints suffered by scavengers in the garbage dump in Benowo Surabaya.

Conflicts of Interest: All authors have no conflicts of interest to declare

Source of Funding: The source of this research costs from self.
Ethical Clearance: The study was approved by Health Research Ethics Committee Faculty of Publich Health Airlangga University No: 154-KEPK

All subjects were fully informed about the procedures and objectives of this study each subject prior to the study signed an informed consent form.

\section{REFERENCES}

1. Soemirat J. Environmental Toxicology. GM University Press; 2005.

2. WHO. Air Quality and Helath. 2014.

3. Studying D, Nurjazuli, Sulistyani. Lung Function Disorders and Factors that Affect It in Employees PT. Semen Tonasa Pangkep South Sulawesi. J Indonesian Environmental Health. 2006;

4. Kumalasari. Risk Factors for Exposure to Ammonia Gas and Hydrogen Sulfide Against Complaints of Health Disorders in Scavengers in Jatibarang Landfill in Semarang City. Dian Nuswantoro University; 2014

5. S Suma'mur. Company Higene and Occupational Health. Jakarta: Mount Agung; 2009

6. Mangesha.Y.A B. A Relative Chronic Effects of Different Occupatioanal dust on Respirator Indeces and Health Of Workers in Three Ethopian Factories. Jour Ind Med. 34:373-80.

7. Nugraheni S. Analysis of Risk Factors for Organic Dust Levels in the Air Against Disorders of Lung Function in Rice Milling Industry Workers in Demak Regency. Diponegoro University; 2004.

8. Bannet W. Lung Disease textbook (Indonesian edition). Jakarta: Faculty of Medicine, University of Indonesia; 1997.

9. Pergub_Jatim no 10. Ambien Air Quality Standards and Emissions of Immovable Sources. 2009. 